\title{
Alteraciones postquirúrgicas del estado cognitivo según el test MoCA en cirugías programadas
}

Salas NM. ${ }^{1}$, Heredia Moreno MF. ${ }^{1}$, Ramírez ML. ${ }^{1}$, Llovera L. ${ }^{1}$, Masso C. ${ }^{1}$, Olaso GB. ${ }^{1}$, Joo Turoni C. ${ }^{2}$, Del Carmen D. ${ }^{1}$, Camporrotondo N. ${ }^{1}$

1 Hospital Ángel C. Padilla, San Miguel de Tucuman, Argentina.

2 INSIBIO - CONICET, San Miguel de Tucuman, Argentina.

Introducción: Las alteraciones cognitivas postoperatorias representan una complicación postquirúrgica frecuente[1]. Una de sus manifestaciones es el Deterioro Cognitivo Postoperatorio (DCP) asociado con el acto anestésico/quirúrgico con una incidencia que varía entre 25 y 80\%[2] independientemente del tipo de cirugía y del tipo de anestesia.

Objetivo: Evaluar el estado cognitivo pre y postquirúrgico luego de la administración de diferentes tipos de anestesias.

Métodos: Se realizó un estudio descriptivo entre marzo y junio de 2019. Se incluyeron 96 pacientes (mayores de 30 años, ASA I-II, de ambos sexos) sin déficit neurológicos, ni alteraciones en la memoria, lenguaje, ni enfermedades psiquiátricas, ni adicción a drogas; los cuales fueron sometidos a cirugías programadas no cardiovasculares realizadas los días martes y jueves en Hospital Ángel C. Padilla de Tucumán. En la visita preanestésica se registró: peso, talla, IMC, factores de riesgo: hipertensión arterial (HTA), diabetes (DBT), tabaquismo, hiper/hipotiroidismo, hiper/ hipoparatoriodismo, depresión, neoplasias, epilepsia e insuficiencia suprarrenal. Se evaluó el estado cognitivo prequirúrgico mediante el test Montreal Cognitive Assessment (MoCA Pre-quirúrgico). En las primeras $24 \mathrm{~h}$ de postoperatorio se realizó nuevamente evaluación del estado cognitivo (MoCA Post-quirúrgico) y evaluación de dolor según escala EVA. Se recolectaron datos de protocolo anestésico: duración de la cirugía, tipo de anestesia, registro de presión arterial y drogas anestésicas. Se aplicó la prueba t de Student o ANOVA según necesidad. Se uso un software PCS.

Resultados: De los 96 pacientes, 59 fueron masculinos y 37 femeninos, con un promedio de edad de 47,03 años y un IMC de 26,44. Según factores de riesgo: HTA $(n=16)$, DBT $(n=14)$, HTA+DBT $(n=9)$, tabaquistas $(n=26)$, epilépticos $(n=6)$. Según tipo de cirugía: abdominales $(n=47)$, traumatológicas $(n=40)$, torácicas $(n=2)$, oncológicas $(n=4)$, urológicas $(n=2)$ y ginecológica $(n=1)$. Según tipo de anestesia: inhalatorias $(n=49)$, endovenosas $(n$ $=8)$, neuroaxiales $(\mathrm{n}=18)$ y combinadas $(\mathrm{n}=21)$. La duración promedio de las cirugías fue de $102 \pm 12$ minutos. Se encontró disminución significativa de MoCA Prequirúrgico 26,1 $\pm 0,3$ vs MoCA postquirúrgico 24,8 \pm 0,4 ( $\mathrm{n}=96$; $\mathrm{p}$ $<0,001)$ según datos agrupados (Figura). La disminución de MoCA postquirúrgico no tubo correlación con la edad, ASA ni dolor postoperatorio.

Conclusión: Independientemente del tipo de cirugía y tipo de anestesia, hubo una disminución significativa del estado cognitivo en el postoperatorio inmediato de los pacientes, probablemente asociado a sus factores de riego. Se requerirá analizar un mayor número de pacientes sanos ASA I (sin factores de riesgo) para determinar si la anestesia disminuye el estado cognitivo en el postoperatorio inmediato según Test MoCA.

https://doi.org/10.25237/congresoclasa2019.69 